\title{
PENGETAHUAN TENTANG MENSTRUASI DENGAN UPAYA PENANGANAN DISMINOREA PADA SISWI MTS AL-HIDAYAH TUNGGUL PAWENANG KECAMATAN ADILUWIH KABUPATEN PRINGSEWU
}

\section{INFO ARTIKEL}

Riwayat Artikel:

Diterima: 17-01-2018

Disetujui: 30-01-2018

\section{Kata Kunci:}

Pengetahuan

Menstruasi,

Penanganan Disminorea

\begin{tabular}{l} 
INFO ARTIKEL \\
\hline Riwayat Artikel: \\
Diterima: 17-01-2018 \\
Disetujui: 30-01-2018
\end{tabular}

\author{
Surmiasih', Depin Priyati2 \\ STIKes Aisyah Pringsewu \\ surmiasih12@gmail.com ${ }^{1}$, depinpriyati95@gmail.com ${ }^{2}$
}

\begin{abstract}
ABSTRAK
Abstrak: Masa remaja merupakan tahapan antara masa kanak-kanak dengan masa dewasa biasanya mulai dari usia 14 tahun pada pria dan usia 12 tahun pada wanita. Pada remaja putri khususnya ditandai dengan dimulainya siklus menstruasi. Salah satu gangguan menstruasi adalah dismenore. Angka kejadian nyeri menstruasi di dunia cukup besar, rata-rata lebih dari $50 \%$ perempuan di setiap Negara mengalami nyeri menstruasi. Kriteria umur remaja berkisar antara 10-19 tahun. Tujuan dari penelitian ini untuk mengetahui pengetahuan tentang menstruasi dengan upaya penanganan dismenorea di MTs Alhidayah Tunggul Pawenang Kecamatan Adiluwih Kabupaten Pringsewu. Penelitian ini merupakan penlitian kuantitatif dengan desain cross sectional. Waktu pelaksanaannya pada bulan juni 2017 di MTs Alhidayah Tunggul Pawenang Kecamatan Adiluwih Kabupaten Pringsewu. Populasi pada penelitian ini adalah siswi kelas 1 dan 2 sejumlah 67 siswi.. Pengambilan sampel dengan menggunakan total populasi.Hasil penelitian menunjukan bahwa ada hubungan antara pengetahuan tentang menstruasi dengan upaya penanganan dismenorea didapatkan pvalue 0,001 $(<0.05)$. Diharapkan hasil penelitian ini dapat menambah wawasan para siswi pengetahuan tentang menstruasi dengan upaya penanganan dismenorea, serta meningkatkan kemampuan siswi untuk melakukan penanganan pada saat dismenorea.
\end{abstract}

\begin{abstract}
Adolescence is a stage between childhood and adulthood usually ranging from the age of 14 years in men and 12 years of age in women. Young women in particular are characterized by the start of the menstrualcycle. One of menstrual disorders is dysmenorrhoea. The rate of menstrual pain in the world is quite large, on average more than 50\% of women in every country experience menstrual pain. When the age of adolescents ranged from 10-19 years. The purpose of this study to determine the relationship of knowledge about menstruation with the efforts of handling dysmenorrhoea in MTs Al-hidayah Tunggul Pawenang Adiluwih Pringsewu. The type of research used in this study is quantitative. The research design used was cross sectional. The time of its implementation in June 2017. in MTs Al-hidayah Tunggul Pawenang Adiluwih Pringsewu. Population in this research is student of class 1 and 2 number of 67 student. Sampling using total population. The result of analysis shows that there is a relationship between knowledge about menstruation with the effort of handling dysmenorrhoea obtained p-value 0,001 $(<0.05)$. It is expected that the results of this study can increase the insight of the students of knowledge about menstruation with the handling of dysmenorrhoea. And increase the willingness of students to perform treatment at the time of dysmenorrhoea.
\end{abstract}




\section{A. LATAR BELAKANG}

Masa remaja adalah suatu tahapan antara masa kanak-kanak dengan masa dewasa. Istilah ini menunjukkan masa dari awal pubertas sampai tercapainya kematangan, biasanya mulai dari usia 14 tahun pada pria dan usia 12 tahun pada wanita. Pertumbuhan dan perkembangan pada masa remaja sangat pesat berlangsung pada usia 11-16 tahun pada laki-laki dan 10-15 tahun pada perempuan (Samadi, 2004). Remaja perempuan pada masa baliq mempunyai beberapa masalah meliputi perkembangan sikap kewanitaan, perubahan fisik, kondisi siklus menstruasi, jerawat, kegemukan dan penyakit (Samadi, 2004).

Kesehatan Reproduksi Remaja (KRR) dari tenaga kesehatan maupun dari institusi kesehatan. Saat seseorang memasuki masa remaja terjadi berbagai perubahan baik fisik maupun mental. Pada remaja putri khususnya ditandai dengan dimulainya siklus menstruasi. Menstruasi dikenal dengan nama lain haid atau datang bulan dimana adanya perubahan fisiologis dalam tubuh manusia yang terjadi secara berkala dipengaruhi oleh hormone repsoduksi baik FSH-Estrogen atau LHProgesteron. Umumnya darah yang dikeluarkan akibat mestruasi sekitar $10 \mathrm{~mL}$ sampai $80 \mathrm{~mL}$ dengan rata-rata biasanya sekitar $35 \mathrm{~mL}$ per hari (Harry, 2016).

Beberapa gangguan menstruasi diantaranya adalah sindroma premenstruasi, amenore, dismenorea, hipermenore dan hipomenore (Prawiroharjo, 2011). Namun yang paling sering ditemukan diantara gangguan tersebut adalah dismenore. Dismenorea adalah gangguan atau nyeri hebat/abnomarlitas. Dismenorea dibagi menjadi dua yaitu primer (menstruasi tanpa kelainan genital yang nyata, terjadi dalam 6-12 bulan pertama setelah haid pertama). Dismenorea skunder (nyeri menstruasi yang terjadi karena kelainan organ reproduksi dialami oleh perempuan berusia 30-45 tahun). Salah satu faktor penyebab dismenorea adalah faktor psikis. Faktor psikis ini dapat ditimbulkan oleh stres karena kurangnya pengetahuan remaja tentang menstruasi. Kurangnya pengetahuan remaja ini adalah akibat kurangnya informasi kesehatan yang benar dan kurangnya akses remaja terhadap pelayanan kesehatan reproduksi (Azwar, 2000).

Menurut WHO (World Health Organization) pada tahun 2012, angka kejadian nyeri menstruasi di dunia cukup besar, rata-rata lebih dari 50\% perempuan di setiap Negara mengalami nyeri menstruasi. Kriteria umur remaja berkisar antara 10-19 tahun, menunjukkan bahwa prevalensi ada yang mengalami disminorea dikelompokan menjadi nyeri ringan $19,3 \%$ nyeri sedang $20,2 \%$ dan nyeri yang hebat $60,3 \%$.

Di Indonesia sendiri mencapai 55\% wanita yang mengalami nyeri saat menstruasi (Proverawati dan
Misaroh, 2009). Angka kejadian dismenorea secara menyeluruh di Indonesia sampai saat ini belum dapat dikemukakan karena belum ada data yang lengkap. Pernah dilaporkan di Surabaya angka kejadian dismenore yaitu 1,07-1,31 \% dari jumlah kunjungan penderita di poliklinik ginekologi. Namun angka kejadian ini lebih rendah dari keadaan yang sebenarnya karena tidak semua penderita dismenorre meminta pertolongan ke poliklinik ginekologi (Riskesdas, 2007).

Hasil sensus penduduk tahun 2015 menunjukkan bahwa jumlah penduduk Indonesia yaitu sebesar 237.641.326 jiwa, dan 63,4 juta atau $3,27 \%$ di antaranya adalah remaja umur 10-24 tahun (Sensus Penduduk, 2015). Berdasarkan data dari National Health and Nutrition Examination Survey (NHANES), umur rata-rata menarche (menstruasi pertama) pada anak remaja di Indonesia yaitu 12,5 tahun dengan kisaran 9-14 tahun. Dismenore terjadi pada remaja dengan prevalensi berkisar antara 43\% hingga 93\%, dimana sekitar $74-80 \%$ remaja mengalami dismenore ringan, sementara angka kejadian endometriosis pada remaja dengan nyeri panggul diperkirakan 25-38\%, sedangkan pada remaja yang tidak memberikan respon positif terhadap penanganan untuk nyeri haid, endometriosis ditemukan pada $67 \%$ kasus di laparoskopi (Hestiantoro dkk, 2012).

Hasil Riskesdas Provinsi Lampung menunjukkan bahwa berdasarkan laporan responden yang sudah mengalami haid, rata-rata usia menarche adalah 13 tahun (20,0\%) dengan kejadian lebih awal pada usia kurang dari 9 tahun dan ada yang lebih lambat sampai 20 tahun serta $7,9 \%$ tidak menjawab/lupa. Terdapat $7,8 \%$ yang melaporkan belum haid. Secara nasional rata-rata usia menarche 13-14 tahun terjadi pada 37,5\% anak (Riset Kesehatan Dasar, 2010).

Berdasarkan data dari Badan Pusat Statistik (BPS) 2012, jumlah penduduk perempuan di Kabupaten Pringsewu usia 10-19 tahun yaitu sebanyak 69.797 atau 8,14\% jiwa dari 857.421 jiwa penduduk. Berdasarkan data yang diperoleh dari Dinas Kesehatan Kabupaten Pringsewu, di wilayah Puskesmas Kecamatan Sukoharjo pada tahun 2011, total jumlah kunjungan pasien dismenorea yaitu sebanyak 237 kasus, tahun 2012 meningkat sebanyak 435 kasus, dan tahun 2013 terdapat 424 kasus (Profil Dinas Kesehatan Pringsewu,2013).

Upaya yang dilakukan dalam penanganan disminorea adalah memberikan informasi yang akurat tentang menstruasi. Informasi tersebut misalnya proses terjadinya menstruasi, gangguan menstruasi yang mungkin terjadi, mitos atau kebiasaan yang ada di masyarakat yang berkaitan dengan menstruasi dan sebagainya. Informasi ini dapat diberikan oleh tenaga kesehatan, guru ataupun konselor (Efendi, 2009). Cara untuk mengurangi rasa nyeri saat menstruasi dengan 
olahraga, kompres air hangat, minum obat pengurang nyeri, minum air kunyit, posisi membungkuk, dan istirahat cukup.

Berdasarkan survey pendahuluan yang di peroleh peneliti di Unit Kesehatan Sekolah (UKS) MTs Al hidayah Tunggul Pawenang Kecamatan Adiluwih kunjungan siswi yang pernah ke UKS adalah 89 siswi selama 6 bulan terakhir. Dari jumlah tersebut diambil 10 siswi untuk diwawancarai. Didapatkan hasil 6 (60\%) siswi mengatakan ke UKS karena mengalami nyeri pada saat menstruasi, sedangkan 4 (40\%) siswi ke UKS karena sakit seperti pusing dan batuk. Serta mereka mengatakan di MTs Al hidayah belum pernah ada penyuluhan kesehatan tentang menstruasi dan belum pernah mendapatkan informasi dalam upaya penanganan dismenorea. Dari hasil wawancara didapatkan bahwa siswi ketika dismenorea hanya beristirahat ke UKS atau meminum obat analgesik.

Penelitian ini bertujuan untuk mengetahui tentang hubungan pengetahuan remaja tentang mestruasi dengan upaya penanganan disminorea di MTs Al hidayah Tunggul Pawenang.

\section{B. METODE PENELITIAN}

Jenis penelitian ini adalah kuantitatif dengan menggunakan desain Cross Sectional Penelitian dilakukan pada bulan Juni 2017 di MTs Alhidayah Tunggul Pawenang Kecamatan Adiluwih Kabupaten Pringsewu. Populasi pada penelitian ini adalah seluruh siswi kelas 1 dan 2 di MTs Al hidayah dengan jumlah 109 siswi. Sampel dalam penelitian ini adalah siswi yang sudah menstruasi dan mengalami disminorea sejumlah 67 siswi. Teknik pengambilan sampel dalam penelitian ini menggunakan total sampling. Instrumen penelitian yang digunakan adalah kuesioner yang berisi tentang pengetahuan menstruasi dan upaya penanganan disminorea.

\section{HASIL DAN PEMBAHASAN}

\section{Analisis Univariat}

TABEL 1

Distribusi Frekuensi Pengetahuan Menstruasi di MTs Al-Hidayah Tanggul Pawenang

\begin{tabular}{|l|c|c|}
\hline \multicolumn{1}{|c|}{ Pengetahuan } & Frekuensi & Persentase (\%) \\
\hline Kurang Baik & 44 & 65.7 \\
\hline Baik & 23 & 34.3 \\
\hline Total & 67 & 100.0 \\
\hline
\end{tabular}

Berdasarkan hasil penelitian didapatkan bahwa dari 67 responden $44(65,7 \%)$ responden memiliki pengetahuan kurang baik dan 23 (334,3\%) responden memiliki pengetahuan baik.
TABEL 2

Distribusi Frekuensi Upaya Penanganan Disminorea di MTs Al-Hidayah Tanggul Pawenang

\begin{tabular}{|l|c|c|}
\hline $\begin{array}{c}\text { Penanganan } \\
\text { Disminorean }\end{array}$ & Frekuensi & Persentase (\%) \\
\hline Kurang Baik & 29 & 43.3 \\
\hline Baik & 38 & 56.7 \\
\hline Total & 67 & 100.0 \\
\hline
\end{tabular}

Berdasarkan hasil penelitian didapatkan bahwa dari 67 responden $29(43,3 \%)$ responden melakukan penanganan disminorea kurang baik dan $38 \quad(56,7 \%)$ responden melakukan penanganan disminorea baik.

\section{Analisa Bivariat}

\section{TABEL 3}

Hubungan Pengetahuan Tentang Menstruasi Dengan Upaya Penanganan Dismenorea di MTs AlHidayah Tanggul Pawenang

\begin{tabular}{|c|c|c|c|c|c|c|c|}
\hline \multirow{3}{*}{$\begin{array}{c}\text { Pengetahu } \\
\text { an }\end{array}$} & \multicolumn{6}{|c|}{$\begin{array}{c}\text { Upaya Penanganan } \\
\text { Disminorea }\end{array}$} & \multirow{3}{*}{$\begin{array}{c}\mathbf{P} \\
\boldsymbol{v} \boldsymbol{e} \\
\boldsymbol{e}\end{array}$} \\
\hline & \multicolumn{2}{|c|}{$\begin{array}{c}\text { Kurang } \\
\text { Baik }\end{array}$} & \multicolumn{2}{|c|}{ Baik } & \multicolumn{2}{|c|}{ Total } & \\
\hline & $\mathbf{N}$ & $\%$ & $\mathbf{N}$ & $\%$ & $\mathbf{F}$ & $\%$ & \\
\hline KurangBaik & 26 & 59.1 & 18 & $\begin{array}{c}40 . \\
9\end{array}$ & 44 & 100 & \\
\hline Baik & 3 & 13.0 & $\begin{array}{l}2 \\
0\end{array}$ & $\begin{array}{c}87 . \\
0\end{array}$ & 23 & 100 & 0.001 \\
\hline Jumlah & 29 & 43.3 & 38 & 56.7 & 67 & 100 & \\
\hline
\end{tabular}

Berdasarkan hasil analisis tentang hubungan pengetahuan tentang menstruasi dengan upaya penanganan dismenorea di MTs Al-Hidayah diperoleh hasil dari 44 responden untuk pengetahuan kurang baik sebesar 26 (59,1\%) responden dengan upaya penanganan disminorea kurang baik dan 18 (40,9\%) dengan upaya penanganan disminorea baik. Sedangkan 23 responden untuk pengetahuan baik, sebesar 3 (13\%) responden dengan upaya penanganan disminorea kurang baik dan 20 (87\%) dengan upaya penanganan disminorea baik. Dapat disimpulkan bahwa ada hubungan antara pengetahuan tentang menstruasi dengan upaya penanganan dismenorea didapatkan p-value $0,001(<0.05)$.

Hasil penelitian hubungan pengetahuan tentang menstruasi dengan upaya penanganan dismenorea di MTs Al-Hidayah diperoleh hasil dari 44 responden untuk pengetahuan kurang baik sebesar $26(59,1 \%)$ responden dengan upaya penanganan disminorea kurang baik dan $18(40,9 \%)$ dengan upaya penanganan disminorea baik. Sedangkan 23 responden untuk pengetahuan baik, sebesar 3 (13\%) responden dengan upaya penanganan disminorea kurang baik dan 20 (87\%) dengan upaya penanganan disminorea baik. Dapat 
disimpulkan bahwa ada hubungan antara pengetahuan tentang menstruasi dengan upaya penanganan dismenorea didapatkan p-value 0,001 (<0.05).

Hasil penelitian ini sejalan dengan penelitian Dinastiti, V (2012), judul penelitian hubungan tingkat pengetahuan penanganan disminorea dengan cara penanganan disminorea mengunakan kompres hangat pada siswi SMAN 1 Pare. Di dapatkan hasil statistic nilai Pvalue $=0,002$ yang berarti ada hubungan tingkat pengetahuan penanganan disminorea dengan cara penanganan disminorea mengunakan kompres hangat.

Hal ini sesuai dengan yang dikemukakan oleh Green (2005) bahwa perilaku seseorang di pengaruhi oleh beberapa faktor salah satunya adalah faktor predisposisi yaitu pengetahuan. Pengetahuan merupakan faktor yang mempermudah atau mempredisposisikan terjadinya perilaku sesorang. Pengetahuan seseorang akan suatu program kesehatan akan mendorong orang tersebut mau berpartisipasi didalamnya. Pada dasarnya, pengetahuan merupakan domain yang sangat penting untuk terbentuknya tindakan seseorang. Perilaku yang didasari dengan pengetahuan akan lebih baik daripada perilaku yang tidak didasari dengan pengetahuan. Salah satu faktor yang mempengaruhi perilaku seseorang adalah pengetahuan. Namun, pembentukan perilaku itu sendiri tidak semata-mata berdasarkan pengetahuan, tetapi masih dipengaruhi oleh banyak faktor yang sangat kompleks.

Setiap bulan wanita melepaskan satu sel telur dari salah satu ovariumnya. Bila sel telur ini tidak mengalami pembuahan maka akan terjadi perdarahan atau disebut menstruasi. Menstruasi terjadi secara periodik, satu bulan sekali. Menstruasi tidak terlepas dari gangguannya salah satunya disminorea atau nyeri perut saat menstruasi. Beberapa gangguan menstruasi diantaranya adalah sindroma premenstruasi, amenore, dismenorea, hipermenore dan hipomenore (Hanifa, 1994). Namun yang paling sering ditemukan diantara gangguan tersebut adalah dismenore.

Dismenorea adalah gangguan atau nyeri hebat/abnomarlitas. Dismenorea dibagi menjadi dua yaitu primer (menstruasi tanpa kelainan genital yang nyata, terjadi dalam 6-12 bulan pertama setelah haid pertama). Dismenorea skunder (nyeri menstruasi yang terjadi karena kelainan organ reproduksi dialami oleh perempuan berusia 30-45 tahun). Salah satu faktor penyebab dismenorea adalah faktor psikis. Faktor psikis ini dapat ditimbulkan oleh stres karena kurangnya pengetahuan remaja tentang menstruasi. Kurangnya pengetahuan remaja ini adalah akibat kurangnya informasi kesehatan yang benar dan kurangnya akses remaja terhadap pelayanan kesehatan reproduksi (Azwar, 2000). Disminorea dapat di kurangi dengan beberapa upaya diantaranya olahraga, kompres air hangat, minum obat pengurang nyeri, minum air kunyit, posisi membungkuk dan istirahat cukup (Haryono, 2016). Upaya lain yang dapat dilakukan adalah dengan kompres dengan botol dingin atau hangat pada bagian yang terasa kram (di perut atau pinggang bagian belakang), minum-minuman hangat yang mengandung kalsium tinggi, menghindari minumminuman yang beralkohol, kopi dan es krim, menggosok-gosok perut atau pinggang yang sakit, ambil posisi menungging sehingga rahim tergantung ke bawah, tarik nafas dalam-dalam secara perlahan untuk relaksasi, obat-obatan yang digunakan harus pada pengawasan dokter. boleh minum analgetik (penghilang rasa sakit) yang banyak dijual di toko obat, asal dosisnya tidak lebih dari 3 kali sehari.

Responden tidak melakukan upaya penanganan disminorea karena kurangnya pengetahuan dan sumber informasi. Saat responden mengalami disminorea upaya yang sering mereka lakukan adalah dengan kompres hangat dan posisi membungkuk atau menganjal perut dengan bantal, selain itu jika sudah tidak tertahankan ada yang meminum analgesik yang diperoleh dari fasilitas kesehatan terdekat. Disminorea yang tidak dilakukan upaya penanganan akan menggangu aktivitas sehari-hari dan merubah kondisi emosi seseorang, sehingga seseorang lebih sensitive terhadap segala hal yang di alaminya. Upaya yang harus dilakukan adalah memberikan sosialisasi kepada responden tentang pengertian menstruasi, tanda gejala, gannguan dan kelainan. Kemudian pengertian disminorea serta cara mengatasi disminorea, karena jika disminorea yang dialami sampai membuat wanita sulit melakukan berbagai hal itu akan menggangu aktivitas terutama proses belajar mengajar pada anak sekolah.

\section{PENUTUP}

\section{Simpulan}

a. Pengetahuan tentang disminorea di MTs AlHidayah Tanggul Pawenang didapatkan hasil sebesar $44(65,7 \%)$ responden dengan pengetahuan kurang baik dan $23(334,3 \%)$ responden dengan pengetahuan baik

b. Upaya penanganan disminorea di MTs AlHidayah Tanggul Pawenang didapatkan hasil 29 (43,3\%) responden kurang baik karena melakukan penanganan disminorea kurang dari 2 upaya dan $38 \quad(56,7 \%)$ responden baik karena melakukan penanganan disminorea lebih dari 2 upaya.

c. Ada hubungan antara pengetahuan tentang menstruasi dengan upaya penanganan 
dismenorea di MTs Al-Hidayah Tanggul Pawenang didapatkan pvalue 0,001 (<0.05).

\section{Saran}

\section{a. Bagi MTs Al-hidayah}

Diharapkan hasil penelitian ini dapat dijadikan masukan agar bekerja sama dengan lintas sektoral terutama dinas kesehatan agar memberi pengetahuan kepada sekolah dan siswa-siswi tentang mentruasi dan dismonorea. Kemudian sekolah dapat menerapkan dan lebih menjelaskan melalui mata pelajaran Ilmu Pengetahuan Alam atau Sains di sekolah tentang menstruasi dan disminorea, sehingga siswi lebih mengerti upaya yang dilakukan saat disminorea dan dapat melakukan penanganan segera.

b. Bagi Responden

Diharapkan dapat meningkatkan pengetahuan siswi tentang menstruasi, tanda gejala, kelainan dan gangguan saat menstruasi termasuk disminorea. Serta dapat menerapkan upaya penanganan disminorea saat menstruasi seperti kompres air hangat, minum obat pengurang nyeri, minum air kunyit, posisi membungkuk dan istirahat cukup, minum-minuman hangat yang mengandung kalsium tinggi, menghindari minum-minuman yang beralkohol, kopi dan es krim, menggosokgosok perut atau pinggang yang sakit dan tarik nafas dalam-dalam secara perlahan untuk relaksasi agar mengurangi nyeri dismonorea dan tidak menggangu aktivitas.

\section{c. Bagi Ilmu Keperawatan}

Diharapkan dapat menjadi masukan dalam memberikan informasi dan mengembangkan asuhan keperawatan khususnya pada bidang keperawatan keluarga khususnya untuk remaja. Dan mengembangkan metode dalam upaya penanganan disminorea.

\section{d. Bagi Peneliti Selanjutnya}

Diharapkan dapat menjadi sumber referensi dan bahan acuan untuk melakukan penelitian selanjutnya serta dapat menambah variabel lain dalam melakukan penelitian dengan menggunakan metode penelitian yang lain dan dengan jumlah responden yang lebih banyak.

\section{DAFTAR PUSTAKA}

Anindita. (2010). Pengaruh kebiasaan minum kunyit asam terhadap keluhan disminorea pada remaja puteri di Surakarta. Jurnal Keperawatan

Azwar. (2000). Hubungan pengetahuan remaja puteri tentang disminorea di SMP N 6
Kalibata Jombang Jawa Barat. Jurnal Keperawatan.

Atik, Leli, \& Rahmawati. (2011). Pengaruh kunyit asa terhadap penanganan nyeri mentruasi pada siswi kelas IX SMA N O1 Sugihwaras. Jurnal keperawatan

Anugroho D. (2010) Faktor-Faktor Penyebab Disminorea. Salemba Medika; Jakarta

Badan Pusat Statistik. (2013). Survey kejadian desminore pada remaja. Diperoleh dari http://sirusa.bps.go.id/.

Bakar, S. A. (2014). Kesehatan reproduksi dan keluarga berencana dalam Tanya jawab. Jakarta. Rajawali Pers

Bare \& Smeltzer. (2002). Faktor resiko terjadinya disminorea. Website diperoleh tanggal 16 oktober 2016.

Bobak, H. (2004). Tahapan Usia remaja. Jakarta. Prenadamedia

Data dan Informasi (Kemenkes RI). (2013). http://www.wordpress.com, (diperoleh tanggal 12 Agustus 2016).

Dahlan, M. D. (2014) Statistik untuk Kedokteran dan Kesehatan (Seri 1 Edisi 6) Epidemiologi Indonesia, Jakarta.

Effendi. (2009). Upaya Penanggulangan Nyeri Saat Menstruasi. Rineka Cipta, Jakarta.

Green .L.W,et al. 2005. Health Program Planning An Educational and Ecological Approach. Fourth edition. New York

Haryono, R. (2016). Siap menghadapi mentruasi dan menopause. Yogyakarta. Gosyen Publishing

Harry. (2016). Kesehatan Reproduksi Remaja. Jurnal Keperawatan

Hestiantoro, dkk. (2012). Hubungan penegtahuan remaja tentang uapaya penanganan disminorea dengan kejadian disminorea di SMP Islam 3 Solo. Jurnal Keperawatan

Lubis, N. L. (2013). Psikologi Kesehatan Reproduksi. Jakarta. Prenadamedia

Marlina. (2012). Pengaruh konsumsi kunyit asam terhadap tingkat nyeri dismenore primer pada remaja puteri di SMA $N$ o1 Tanjung Mutiara. Jurnal keperawatan

Maulana. (2010). Mentruasi, Gejala Dan Penanganannya. ECG; Jakarta

Mansjoer dalam Haryono, R. (2016). Siap menghadapi mentruasi dan menopause. Yogyakarta. Gosyen Publishing

Notoatmodjo. (2003). S. Ilmu Kesehatan Masyarakat Prinsip-Prinsip Dasar. Jakarta.

Notoatmodjo. (2012). Metodologi Penelitian Kesehatan (Edisi Revisi), Rineka Cipta, Jakarta.

Proverawati \& Misaroh. (2009). Kesehatan Reproduksi Wanita. Rineka Cipta, Jakarta.

Pringsewu. (2013). Profil dinas kesehatan pringsewu tentang kunjungan pasien 
diminorea di puskesmas Sukoharjo. Diperoleh tanggal 10 Oktober 2016.

Riskesdas. (2007). Data Kejadian Dismonorea Di Indonesia. Diperoleh tanggal 4 november 2016.

Samadi. (2004). Kesehatan Reproduksi Dan Gangguan-Gangguanya. Graha Ilmu. Yogyakarta

Wulandari \& Anugroho. (2011). Tips Mengatasi Disminorea Pada Remaja. Rineka Cipta, Jakarta. 